by a mathematical analysis, and experimental work on models of this type can therefore be described with some justice as being partly an art and partly a science. Certainly it is a field of work where wide experience is essential, and where results must be subjected to continual scrutiny and comparison with the known behaviour of the natural prototypes.

The concept of regime, first developed on an empirical basis from a study of canals in India, has been found to be of wide application in the field of loose-boundary hydraulics and is itself the subject of basic research at the Station. In its application to uni-directional flow in alluvial channels-an aspect of the subject which is receiving an increasing amount of attention in the United States-regime theory relates the width and depth of a channel to the water discharge, the slope of the water surface and the quantity and nature of material in movement on the bed and in suspension. The application of this theory to hydraulic models is in itself an obvious subject for research.

There would be little point in lis ing all the investigations now in progress at Wallingford, but some idea of the scope of the research programme may be given if a few of the major projects are singled out for mention. Thus in the realm of tidal flow in estuaries, two major investigations of siltation are in progress-one concerning the deterioration of the upper estuary of the Mersey, and the other being aimed at the stabilization and deepening of the shipping channel at and below the port of Chittagong on the Karnafuli River in East Pakistan. A tidal study of a different type is in progress in a rigid-bed model of the tidal Trent, where methods of protection against combinations of river and tidal flooding are being tested. A large proportion of the station's effort is devoted to studies of wave action. In one of the wave basins a large model of the proposed design for the new harbour to be built at I'ema, on the Gold Coast, is being examined to determine its behaviour under the influence of short-period and long-period waves. A model of a now sea wall for the Lincolnshire bank of the outer Humber is being subjected to two-dimensional tests in the 54 -ft. wave tank. 'The formation of a sand-bar across the entrance to Eyemouth Harbour in Berwickshire is boing studied in a $1 / 40$-scale model equipped with pneumatic wave generators. Investigations of river problems and hydraulic structures also figure largely in the Station's programme of applied research and experimentation. In conclusion, mention should be made of radioactive isotopes as tracers for indicating the movements of silt and sand, in the use of which the Hydraulics Research Station, in collaboration with the Atomic Energy Research Establishment at Harwell, has carried out valuable pioneering work.

\title{
OBITUARIES
}

Mr. John Evershed, C.I.E., F.R.S.

By the death on November 17 at the age of ninetytwo of John Evershed, we have lost the doyen of British astronomers. Born on February 26, 1864, at Gomshall in Surrey, he was educated privately and started to work in the chemical industry. He early developed an interest in astronomy and established his own observatory at Kenley in Surrey in 1890. In that year he became one of the founder members of the British Astronomical Association and director of the Section of Solar Spectroscopy. With a small telescope and a spectroscope of his own design and construction, and later with a spectroheliograph also built by himself, he recorded 11,000 solar prominences during his sixteen years work at Kenley. The Evershed solar spectroscope is still an instrument in use to-day.

In 1906 he was appointed assistant director of the Kodaikanal Observatory; in 1911 he succeeded Michie Smith as director, retiring to England in 1923, when he was created C.X.E. in recognition of his work in India. At Kodaikanal he continued his work on prominences and with Mrs. Evershed he published an important memoir on the distribution of prominences during the course of a solar cycle : they noted the excess of eastern over western prominences, the longward displacement of the lines in their spectra and the link between sunspots and metallic prominences. Evershed also greatly improved the quality of the spectroheliograms obtained at the Observatory. His work on sunspot spectra led to his best-known discovery, the radial motion of gases, outwards across the penumbra of a sunspot and inwards at higher levels in the solar atmosphere. This work, published in 1909 , led to his election to the Royal Society in 1915 and to the award of the
Gold Medal of the Royal Astronomical Society in 1918.

Other work carried out by Evershed at Kodaikanal included studies of solar rotation, of the spectra of comets, Venus and Nova Aquilse 1918, of the displacement of lines to the red at the centre and limb of the Sun. He also chose a site for the Cawthron Observatory in New Zealand and travelled to the Vale of Kashmir to find a site with first-class seeing for a solar observatory in India. $\mathrm{He}$ observed eclipses in Norway, 1896; India, 1898; Algeria, 1900 ; Spain, 1905; Australia, 1922 ; and Yorkshire, 1927. Among his eclipse results were tho first record of the chromospheric continuous spectrum at the head of the Balmer series and his successful securing of long exposures on the chromosphere by stationing himself close to the edge of the belt of totality.

On his return from India, Evershed settled at Ewhurst in Surrey, where he built himself an observatory for solar work, continuing to obtain high-class spectroheliograms and high-dispersion solar spectra. His chief point of interest lay in exact wave-lengths of lines in the spectra of prominences and of the centre and limb of the solar disk. In a series of papers, giving measures of the highest degrees of accuracy and continuing until the year 1949, he discussed the varying displacements of lines to the red. He reached the final conclusion that the Einstein gravitational effect was the main cause of the displacements, though the result was modified by Doppler and Lindholm effects. $\mathrm{He}$ also examined some Mount Wilson plates that had been used to determine the general magnetic field of the Sun and concluded that the observed slight displacements were due to localized Doppler effects. 
The last published report of the work of his observatory was for the year 1950. On closing it down finally, he presented some of his instruments to the Royal Greenwich Observatory at Herstmonceux.

Evershed married in 1906 Miss Mary Acworth, and she collaborated actively with him in his researches until her death in 1949. He was married a second time in 1950, to Miss Margaret Randall, who survives him. F. J. M. StratToN

\section{Dr. A. J. Carlson}

When he died on September 2, Dr. Anton Julius Carlson bore the illustrious title of "Frank P. Hixon distinguished service professor emeritus of physiology, University of Chicago".

Carlson was born in Sweden in 1875 and went to the United States in 1891. He graduated A.B. at Augustana College, Rock Island, Illinois, in 1898, A.M. the following year, and Ph.D. in physiology at Stanford University in 1903. After spending one year as a research associate at the Carnegie Institution, he joined the Department of Physiology of the University of Chicago in 1904 and remained there until he retired in 1940 from the positions of professor and chairman of the Department. As professor emeritus he continued actively at work, and himself told a Committee of the House of Representatives in 1950 that "for the last ten years I have been emeritus or demeritus, whatever you call it; however, the only thing I retired from ten years ago was my salary". In the U.S. Army during 1917-19 he was a lieutenant-colonel in the Sanitary Corps, and while serving in Sweden was given the honorary degree of M.D. by Lund. He held honorary degrees from seven universities.
Carlson's early work was on the rate of conduction of impulses in nerves and, after some excursions into the comparative physiology of the circulation, he did his main work upon the physiology of the alimentary tract and of the visceral sensory nervous system. Apart from some two hundred papers, he wrote two books : "Control of Hunger in Health and Disease" and "The Machinery of the Body".

Carlson was honoured by many institutions. He was elected to the U.S. National Academy of Sciences in 1918, to the American Physiological Society in 1904 (being secretary during 1910-14 and president 1923-25), and to a variety of others in the United States and abroad. He had also served as president of the American Association for the Advancement of Science, the American Biological Society, the Federation of American Societies for Experimental Biology, the Institute of Medicine, the American Association of University Professors, and the National Society for Medical Research. In 1935 he lectured in China under the auspices of the Rockefeller Foundation, and he was $a_{0}$ frequent traveller, attending seven international physiological congresses between 1909 and 1950, and the international gerontological congress in London last year.

Carlson was a great teacher, and himself said that he had taught between 8,000 and 10,000 medical students, and 75,000-100,000 other students. He was forthright, very outspoken and a keen controversialist. His work as a consultant on Government organizations (such as the Food and Drug Administration and the Office of Scientific Research and Development) often enlivened meetings; but surprising though his statements sometimes appeared, they were always backed by experimental facts, often elicited in his own laboratory.

H. M. Sinclair

\section{NEWS and VIEWS}

\section{Hungary : American Scientists' Resolutions}

THE U.S. National Academy of Sciences at its autumn meeting in Washington adopted the following resolution respecting recent events in Hungary: "Those members of the National Academy of Sciences of the United States of America present at a meeting in Washington on November 10, 1956, unite in expressing their profound admiration and sympathy to fellow scientists in Hungary and to all the men and women of that nation who have demonstrated their love of liberty with sacrificial devotion during the tragic events of the past few weeks. American scientists look forward with hope to a time when their Hungarian colleagues, freed from external oppression, will be able to join fully in the international exchange of information, discussion and encouragement which is essential to the progress of seience". Dr. Detlev W. Bronk, president of the Academy, expressed his satisfaction that the Academy's resolution could be associated with a similar statement adopted by the American Philosophical Society. "It is appropriate," he said, "that the Academy should join with the American Philosophical Society, the oldest of the great scholarly societies of the United States, in a matter so closely related to the unconquerable yearning of mankind freely and courageously to advance its highest human and cultural ideals. The statements of the Academy and of the Society recognize with humility and deep gratitude the desperate and courageous struggle of
Hungarians for those principles which are precious to all who value the right to seek truth and to teach it freely."

\section{Institute of Metals : Awards}

THE Institute of Metals have made the following awards: Institute of Metals (Platinum) Medal for 1957 : Dr. Maurice Cook, joint managing director, Imperial Chemical Industries, Ltd., Metals Division, in recognition of his outstanding contribution to the science of metallurgy, to the non-ferrous metals industry and to the welfare of the metallurgical profession; Rosenhain Medal for 1957: Dr. H. K. Hardy, research manager, United Kingdom Atomic Energy Authority, Industrial Group, in recognition of his outstanding contributions to knowledge in the field of physical metallurgy.

\section{University of Leeds Appeal}

IMMEDIATELY before the War the number of fulltime students at the University of Leeds was about 1,750. The number has now increased to 3,700 and, among these, the number reading science or technology has grown from 560 to 1,700 . In five or six years time it is expected that there will be 5,300 students in all, of whom 3,000 will be reading science or technology. During the past sixteen years the research work of the University has developed at a rapid rate and will develop even more quickly in the next five or six years. To meet these demands, the 